Journal of the

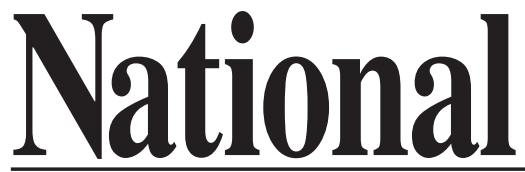

Academy or

Forensic
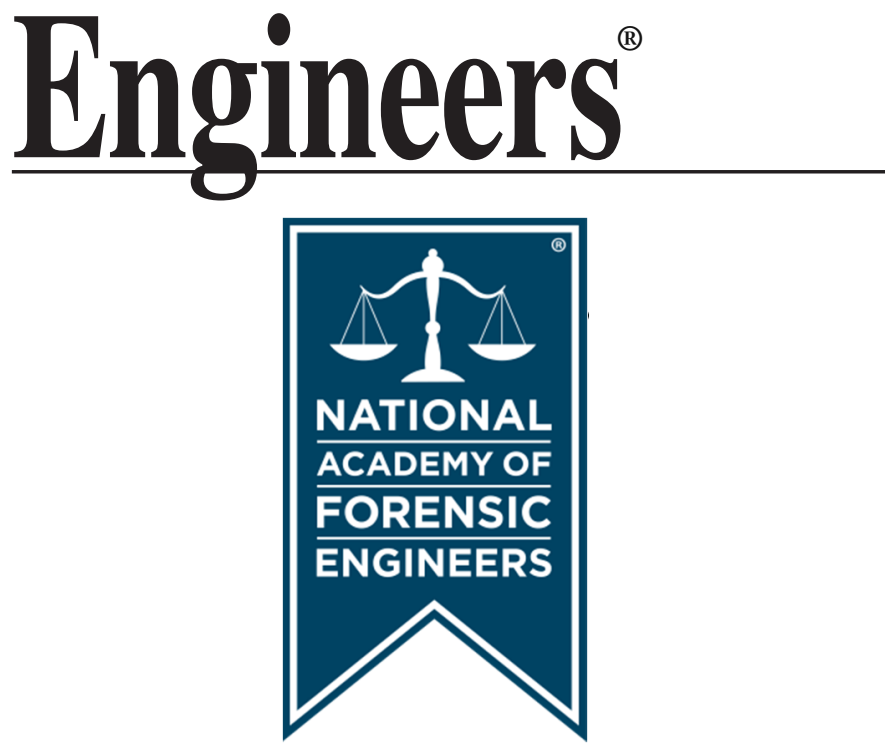

http://www.nafe.org ISSN: 2379-3252 


\section{Forensic Engineering Comparison of Two \& Three Dimensional Photogrammetric Accident Analysis}

by Richard M. Ziennicki, Ph.D., P.E. (NAFE 308S) and Stephen J. Fenton. P.E.

\section{Introduction}

One of the challenges for an accident reconstructionist is to create accurate scene diagrams from photographs. There are several software packages on the market today that allow engineers to gather dimensions from photographs through photogrammetric analysis. However, not all photogrammetric software performs the same functions. In short, the software is classified as either twodimensional (2-D) or three-dimensional (3-D) photogrammetric software. 2-D photogrammetry software accurately rectifies a photograph given certain 2-D data from the scene such as the length of lane lines and/or the width of the roadway. 3-D software needs more data to perform the rectification, and without additional data, the photogrammetric analysis can be inaccurate. The strength of the 3-D photogrammetric software is its ability to create scaled three-dimensional computer models. This paper discusses the application of 2-D and 3-D photogrammetry in accident analysis and reconstruction.

\section{Background}

Photogrammetry is a process used to scale images from photographs. If there are at least two photographs of an item taken at different angles, the item can be accurately scaled using photogrammetry. The state-of-the-art documentation technique called "close-range photogrammetry" allows engineers and accident reconstructionists to create 2-D models of the accident scene and 3-D computer models of vehicle damage utilizing photographs.

Typically, accident reconstruction begins with several photographs of an object or scene. The photographs are then imported and displayed on-screen where a computer user references common points of each photograph: refer to Figures 1,2, and 3. The information contained on the photographs is then processed. When processing, the photographs are combined, camera stations are calculated, and the referenced points are located in 2-D or 3-D space. The referenced points make up lines and polygons in a 2-D or 3-D coordinate system. The result is a 2-D or 3-D model that can be scaled and transferred to a threedimensional software program such as AutoCAD. 


\section{2-D Photogrammetry}

In accident reconstruction, it is often necessary to create a scaled accident scene diagram that includes the location of skid marks, vehicle position and impact location. Typically, when an accident reconstructionist investigates the accident scene, skid marks have faded and debris has washed away. However, police photographs taken at the accident scene document the location of this information. Utilizing 2-D photogrammetry, an accident reconstructionist can create scalable diagrams that incorporate data documented in the police photographs. The process that enables a user to create an accurate accident scene diagram from as little as one police photograph is the combination of inverse camera projection and photographic rectification.' This process requires that the accident site be available or that a reconstructionist knows the coordinates of four points on the accident scene. A graphical example of this process is shown in Figures 4 and 5.

\section{3-D Photogrammetry}

The advantage of 3-D photogrammetry over 2-D photogrammetry is that not only "flat" accident scenes can be recreated in scale, but also 3-D accident scenes along with objects such as landmarks, vehicles, and roadway markings.

Using 3-D photogrammetric techniques, engineers can digitize accident scene photographs to create accurate three dimensional computer models of the vehicles. The 3-D vehicle models are used to quantify the crush damage for each vehicle, and then equivalent barrier speed is determined. ${ }^{2}$ The 3-D scene and vehicle models created with photogrammetry can then be imported into 3-D computer software such as "3-D Studio MAX". Utilizing this software, vehicles can be viewed from any "camera" location at any angle. Furthermore, the events of the accident can be animated.

\section{Application}

Knott Laboratory, Inc. has utilized 3-D photogrammetry on cases worldwide including the Princess Diana accident in France. ${ }^{3}$

The Mercedes 280S, where Princess Diana was the right rear occupant, was fully recreated using photogrammetry as shown in Figure 6. The crash damage was recreated in scale, as shown in Figure 7, then used to calculate crash energy and equivalent barrier speed for the Mercedes.

\section{Case Study}

An example application of 3-D photogrammetry, together with 3-D computer modeling and computer animation, is a reconstruction of a police shooting accident reconstructed by these authors. ${ }^{4}$ 
The incident occurred after midnight in a parking lot just outside a bar. The patrons from the bar began filtering out when a fight was initiated. As two offduty police officers from inside the bar proceeded to investigate the disturbance, the events of the early morning began to unravel. As the officers were approaching to investigate a stationary Acura, the vehicle abruptly backed up, striking one of the officers. With the police officers firing their weapons to stop the vehicle, the Acura continued in reverse throwing the officer aside and to the ground. After the Acura finished backing up, it began to move forward, traveling toward the officer as he was coming to his feet. Several of the bar patrons witnessed the incident but none of the statements given were consistent.

\section{Analysis}

Knott Laboratory reconstructed the police shooting incident a year and a half after the incident. The Acura was not made available to Knott Laboratory until nineteen months after the incident occurred, during which time many pieces of evidence associated with the Acura were no longer available. The rear. front passenger, and front driver windows were no longer intact. Bullets that penetrated the windows caused the glass to shatter where environmental and aging effects caused the glass to deteriorate and crumble. When the engineers first inspected the Acura, the glass from each of the three windows was shattered and spread throughout the vehicle. The condition of the glass made the reconstruction of the shooting incident nearly impossible. The three missing windows contained valuable evidence associated with the directions the bullets traveled through the holes. It was vital to place the bullet entrances through the windows in 3-D space to determine the bullet trajectories and to accurately reconstruct this incident. Application of 3-D photogrammetry of photographs taken by police at the accident scene allowed these engineers to create an accurate 3-D model of the vehicle and the bullet trajectories.

These authors were able analytically to "rebuild" the Acura, replace the bullet-ridden windows, and reconstruct the incident by utilizing the following state-of-the-art tools:

- 3-D Photogrammetry

- Three-dimensional Computer Modeling

- Time/Space Animation Analysis

Figures 8 and 9 illustrate the phases of the photogrammetry and the 3-D computer model that was created using photogrammetry. 


\section{Conclusions}

Photogrammetry is a powerful tool that has gained popularity in the United States in recent years. An accident reconstructionist can use photogrammetry to create accurate and to-scale accident scene diagrams based on as little as one photograph; it can create 3-D models of the vehicles to calculate crash energy, and finally, can create accurate accident animation. The advantage of photogrammetry is that the entire process can be accomplished on a desktop computer, utilizing scanned images and Photo-CD images. The 3-D photogrammetry has been presented by these authors and accepted in State and Federal courts.

\section{References}

1. Fenton, Stephen and Kerr, Richard. "Accident Scene Diagramming Using New Photogrammetric Technique", Society of Automotive Engineers (SAE) paper 970944.

2. Fenton, Stephen and Ziernicki, Richard. "Using Digital Photogrammetry to Determine Equivalent Barrier Speed (EBS)", Society of Automotive Engineers (SAE) paper 1999-01-0439.

3. Fenton, Stephen. "Reconstructing the Princess Diana Crash", Law Enforcement Technology, August 1998.

4. Reconstruction of a Motor Vehicle Accident Involving a Police Shooting Using Photogrammetry and 3-D Computer Modeling, by Richard Ziernicki, Ph.D., P.E., Stephen J. Fenton, P.E., Wendy S. Johnson, B.Sc.C.E., James M. LaRocque, B.Sc.C.E., David A. Danaher, B.Sc.M.E., Nathan A. Rose, B.Sc.C.E., and Robert S. Hoit, B.Sc.C.M., Accident Reconstruction Journal, in press. 
Copyright @ National Academy of Forensic Engineers (NAFE) http://www.nafe.org. Redistribution or resale is illegal. Originally published in the Journal of the NAFE volume indicated on the cover page. ISSN: 2379-3252

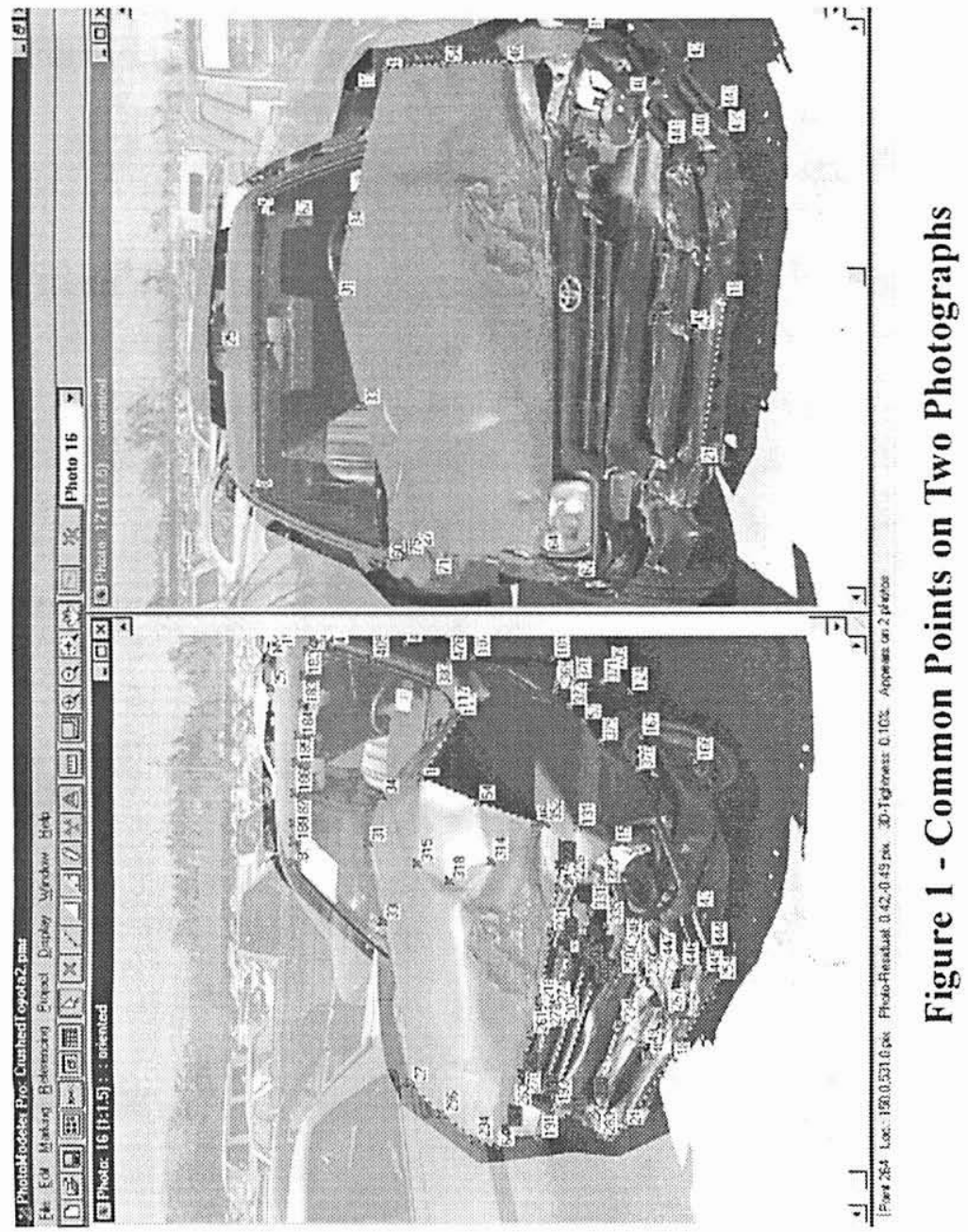


Copyright $\odot$ National Academy of Forensic Engineers (NAFE) http://www.nafe.org. Redistribution or resale is illegal. Originally published in the Journal of the NAFE volume indicated on the cover page. ISSN: $2379-3252$

PAGE 90 Originally published in the Journal of the NAFE volume indica

NAFE 3085

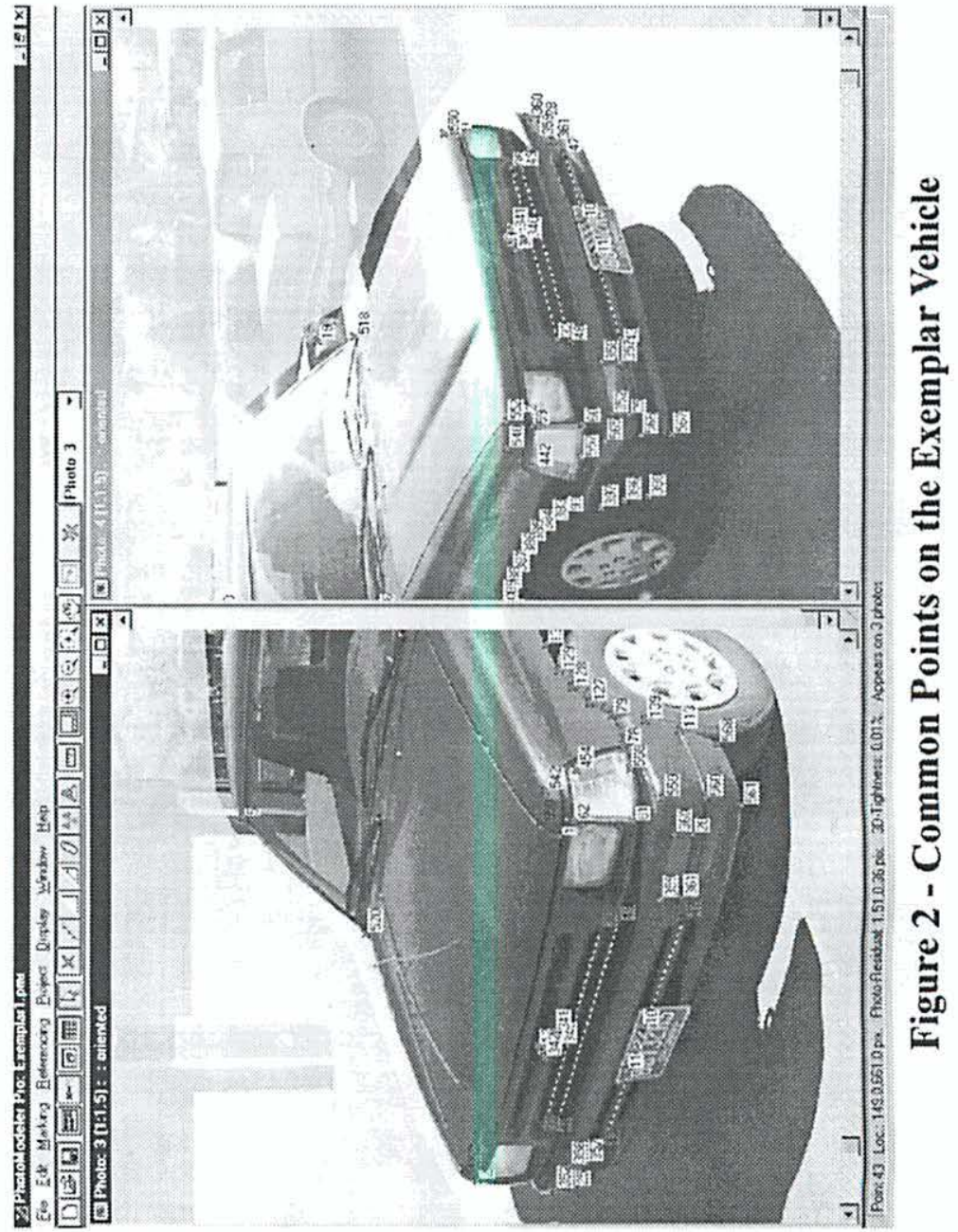


Copyright @ National Academy of Forensic Engineers (NAFE) http://www.nafe.org. Redistribution or resale is illegal. Originally published in the Journal of the NAFE volume indicated on the cover page. ISSN: 2379-3252

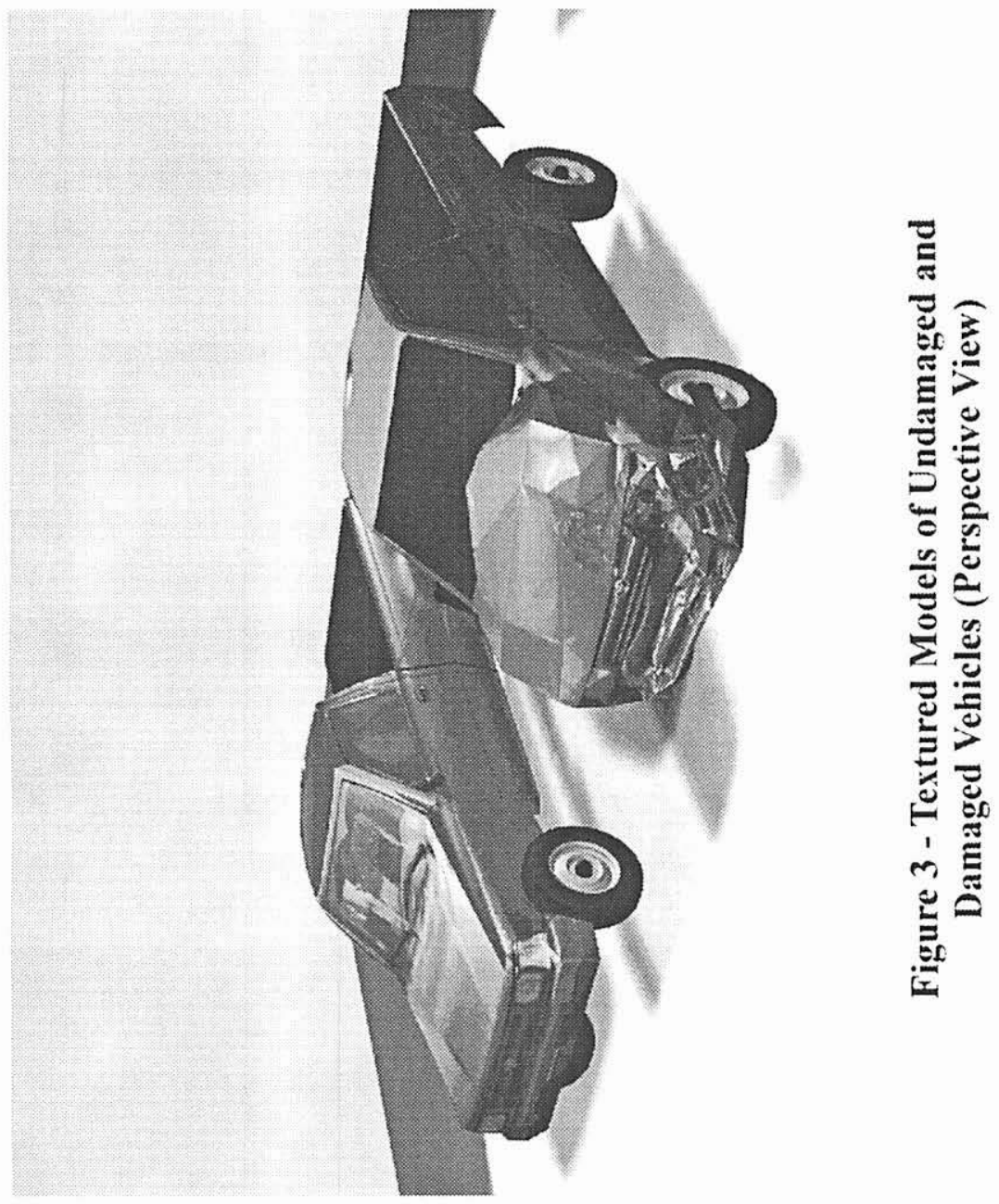


Copyright @ National Academy of Forensic Engineers (NAFE) http://www.nafe.org. Redistribution or resale is illegal. PAGE 92 Originally published in the Journal of the NAFE volume indicated on the cover page. ISSN: 2379-3252
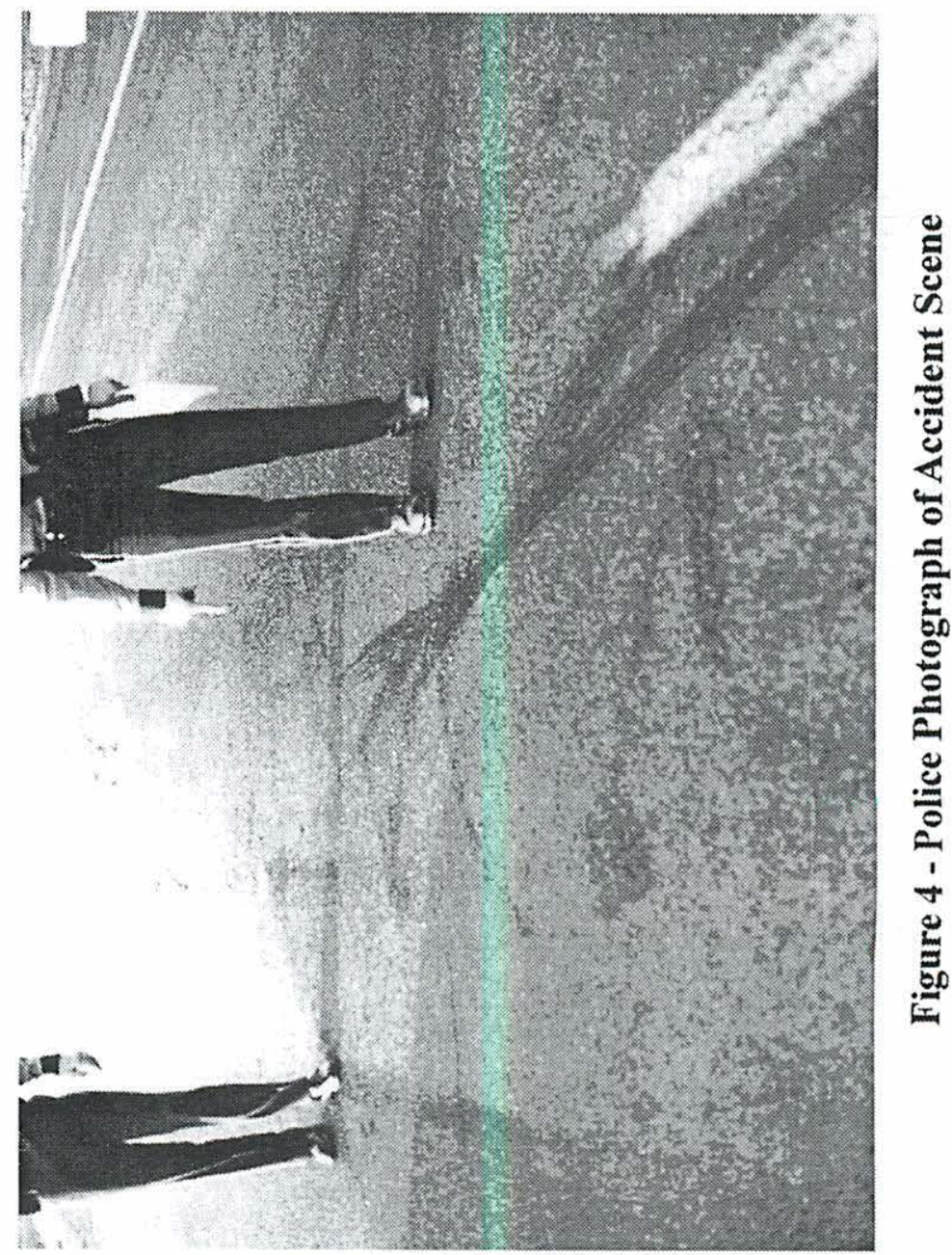
Copyright $\odot$ National Academy of Forensic Engineers (NAFE) http://www.nafe.org. Redistribution or resale is illegal. Originally published in the Journal of the NAFE volume indicated on the cover page. ISSN: $2379-3252$

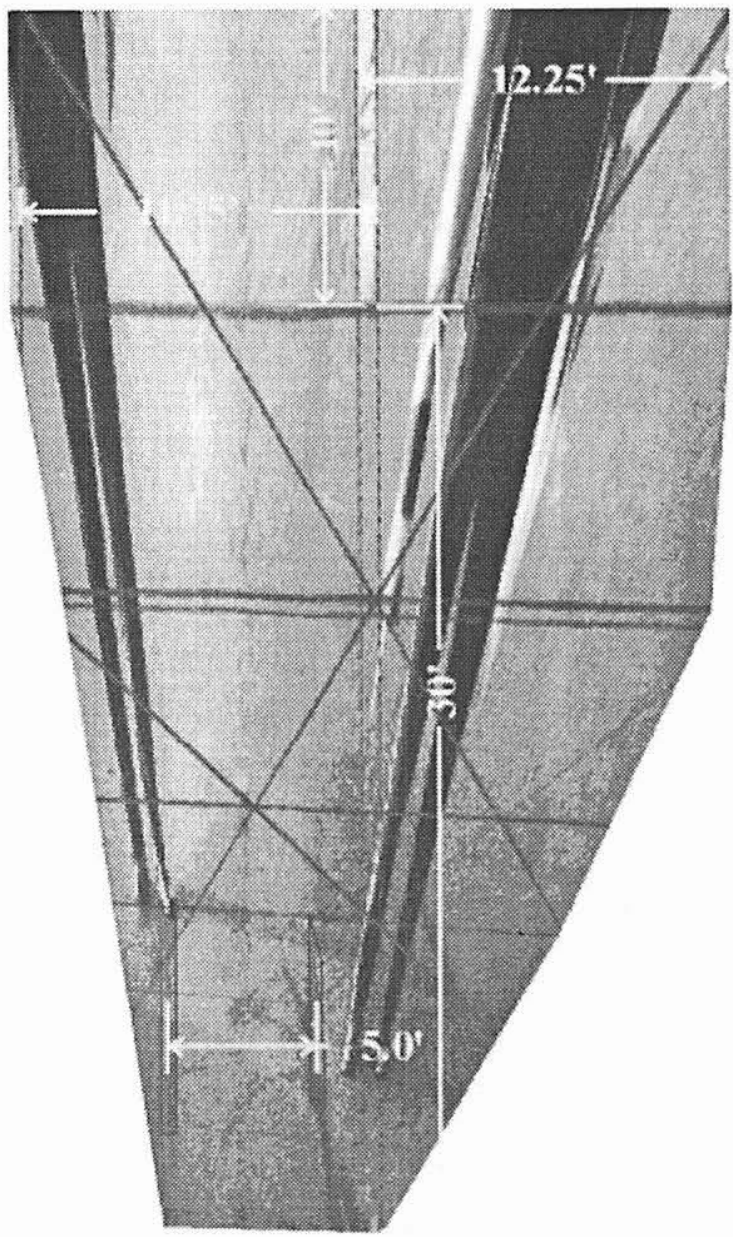

Figure 5 - Rectified Photograph 
Copyright @ National Academy of Forensic Engineers (NAFE) http://www.nafe.org. Redistribution or resale is illegal. Originally published in the Journal of the NAFE volume indicated on the cover page. ISSN: 2379-3252

\section{PAGE 94}

JUNE 2000

NAFE $308 S$

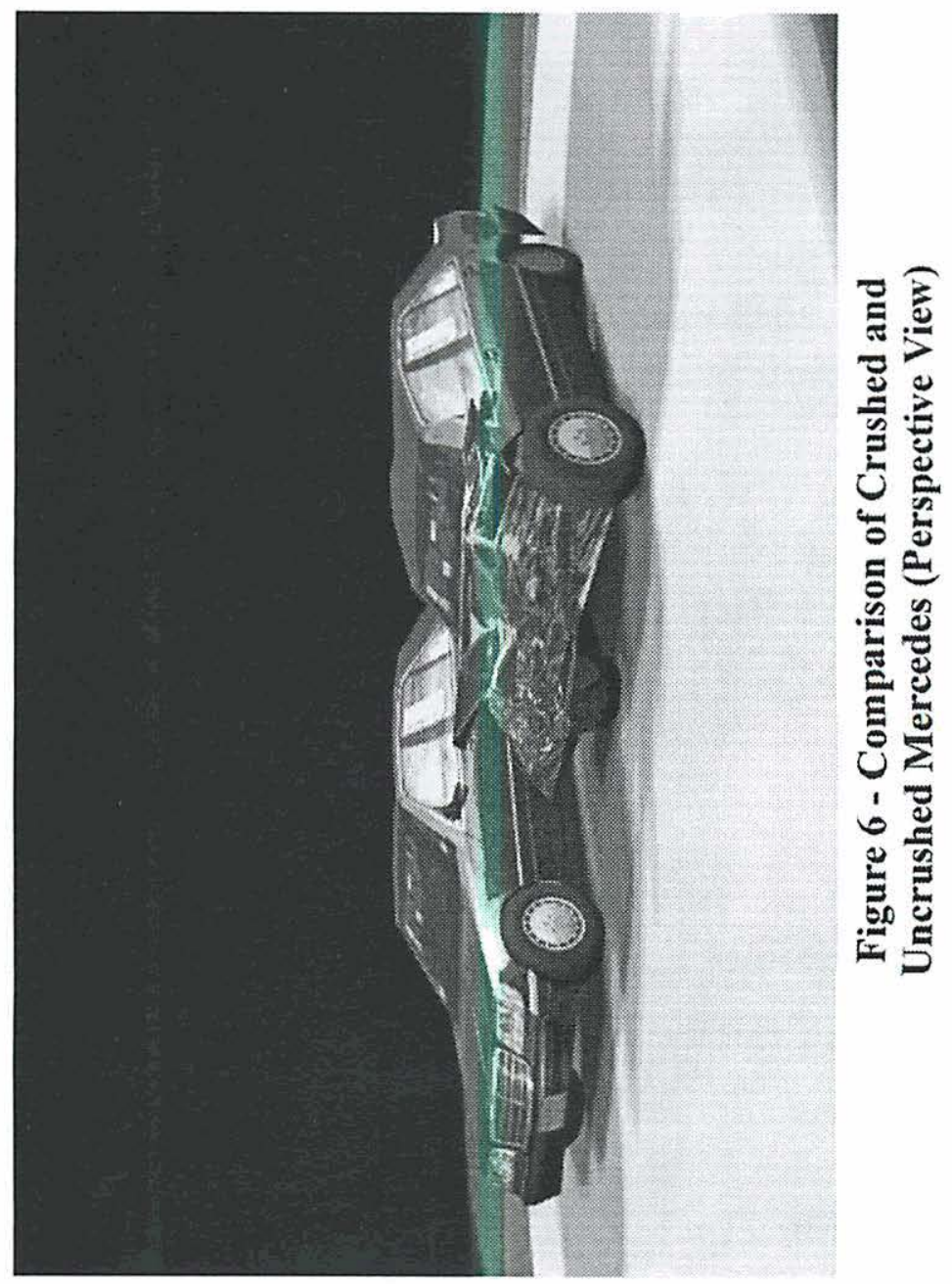


Copyright (C) National Academy of Forensic Engineers (NAFE) http://www.nafe.org. Redistribution or resale is illegal. Originally published in the Journal of the NAFE volume indicated on the cover page. ISSN: 2379-3252

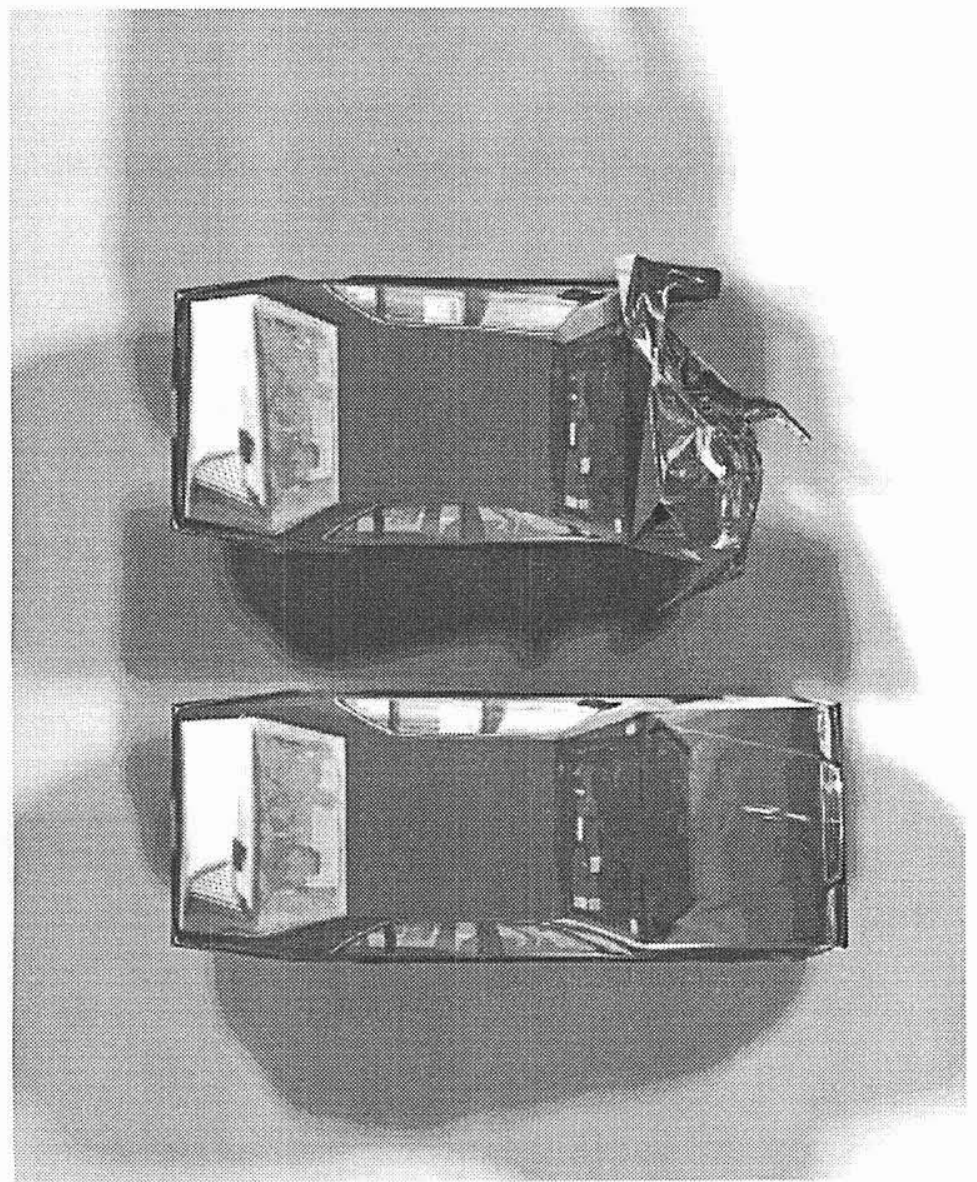

\section{Figure 7 - Comparison of Crushed and Uncrushed Mercedes (Top View)}


Copyright (C) National Academy of Forensic Engineers (NAFE) http://www.nafe.org. Redistribution or resale is illegal.

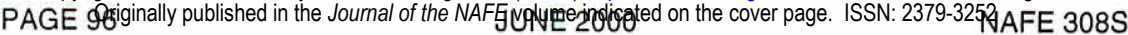

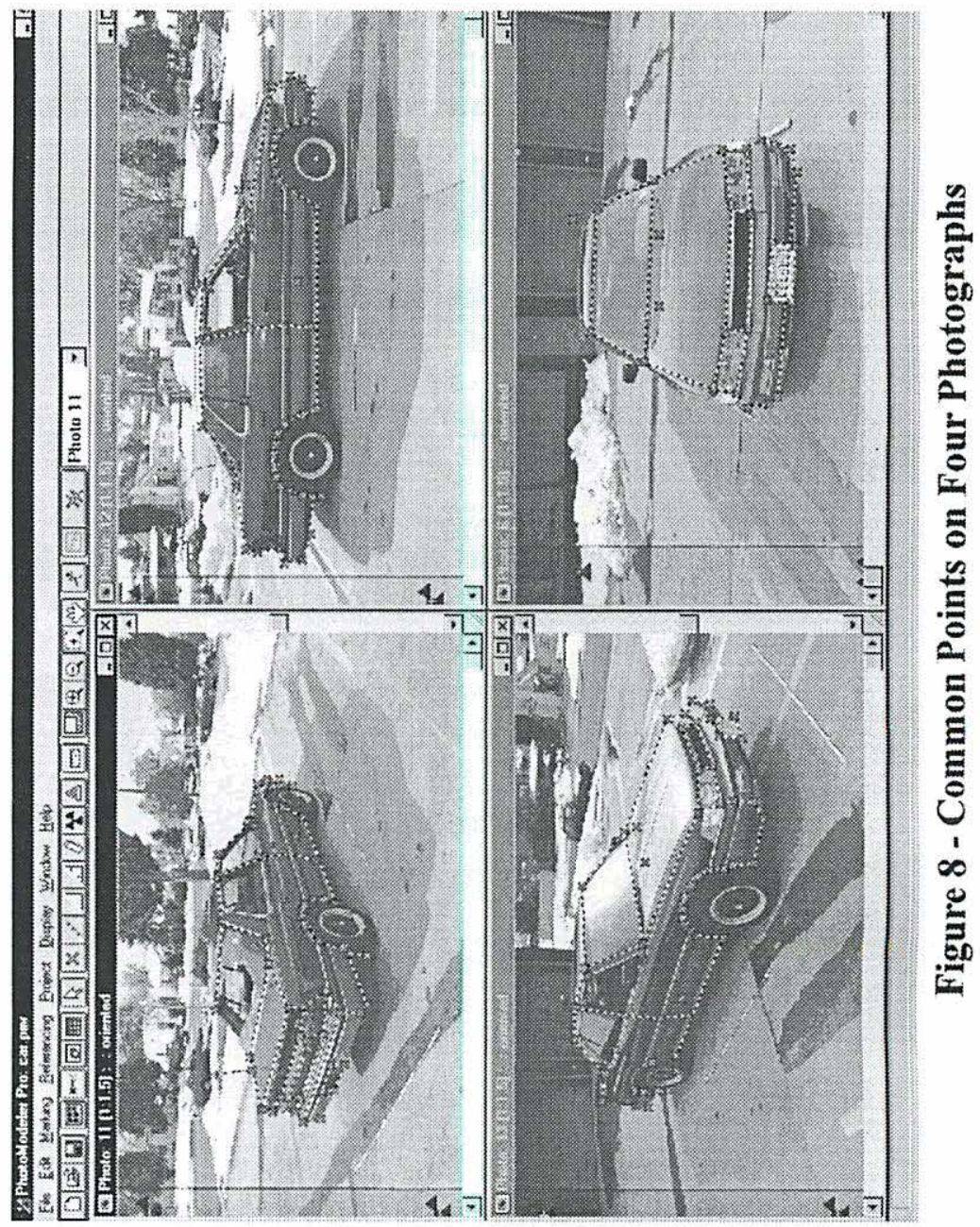


Copyright $\odot$ National Academy of Forensic Engineers (NAFE) http://www.nafe.org. Redistribution or resale is illegal. Originally published in the Journal of the NAFE volume indicated on the cover page. ISSN: 2379-3252

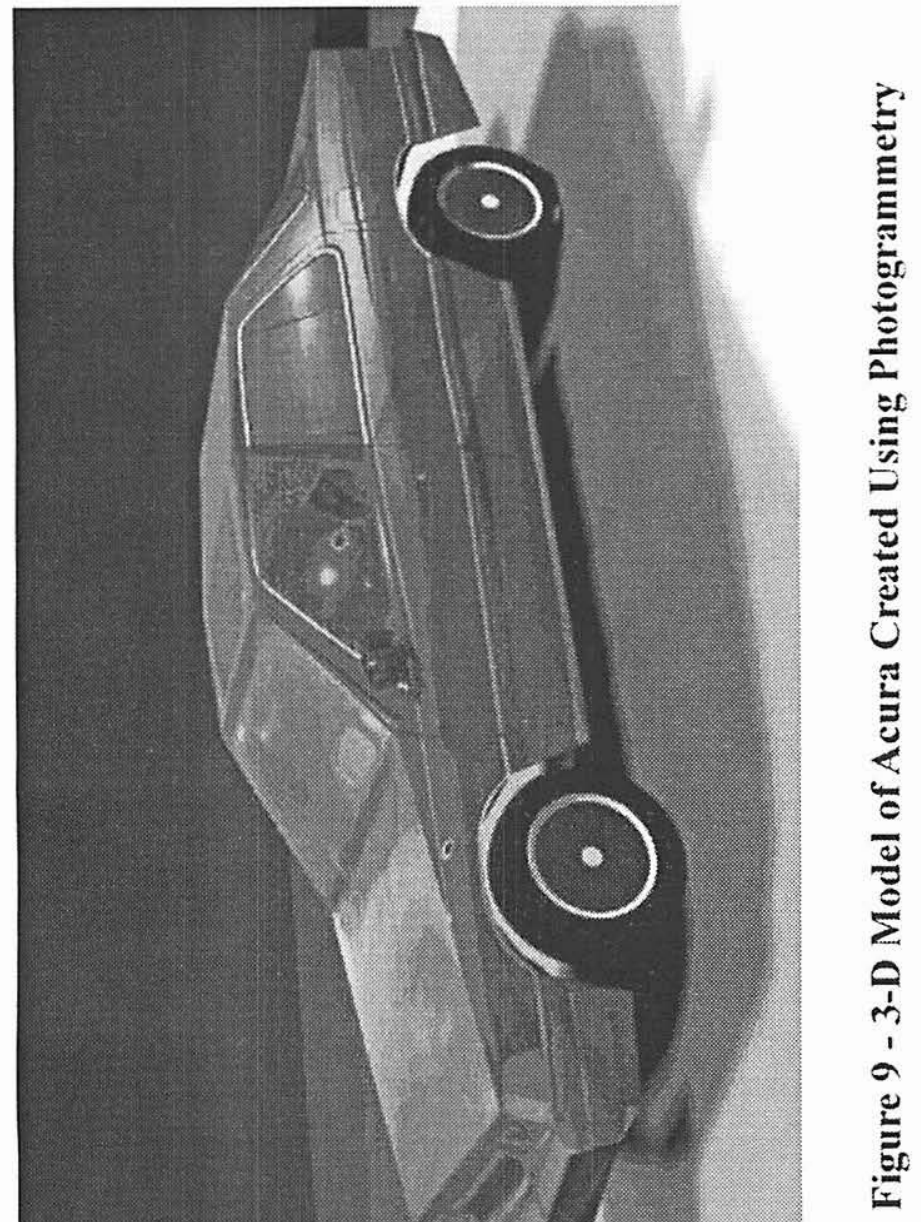

